\title{
Editorial
}

\section{Envelhecimento, adesão à terapia medicamentosa e a educação em saúde}

\author{
Silvio Luis Rodrigues de Almeida*, Meives Aparecida Rodrigues de Almeida**
}

Nas últimas décadas a composição etária da população dos países ocidentais tem sofrido alterações constantes, e os idosos compreendem uma parcela cada vez maior. O principal impacto que o envelhecimento populacional traz para o sector de saúde é uma importante alteração nas causas de morbimortalidade. As doenças infecto-contagiosas cedem lugar às doenças crônico-degenerativas, que se tornam progressivamente mais prevalentes, obrigando seus portadores a procurarem os serviços de saúde com grande frequência.

O idoso apresenta invariavelmente índices maiores de morbidade quando comparados aos demais grupos etários. A polipatologia inevitável parece guiar para a polifarmácia, uma condição mais frequente no idoso do que na população jovem. A maioria dos idosos consome pelo menos um medicamento, e cerca de um terço deles consome 5 ou mais simultaneamente, sendo que a média oscila entre 2 e 5 medicamentos [1]. Além disso, apresentam uma série de características peculiares que induz a uma maior complexidade, no momento da abordagem terapêutica. Esta mais complexa terapia medicamentosa adicionada à baixa informação sobre o seu uso pode levar a maiores problemas na administração de seus medicamentos, tendo em vista que a maioria das orientaçóes durante a consulta é verbal, o que aumenta a possibilidade de erro.

Muito embora os idosos possam talvez não fazer mais erros de medicação do que os jovens, as consequências deletérias podem ser mais sérias, menos facilmente detectadas e menos facilmente resolvidas do que em pacientes de menor idade. Desta forma, erros de medicação são um sério problema em potencial, implicando em aspectos clínicos e sociais de alta relevância, tendo em vista a saúde do paciente e o custo social que isso gera.

Pacientes que deixam de tomar as suas medicaçóes corretamente podem não responder à terapia. Assim, na próxima consulta, o médico pode avaliar que o paciente náo evoluiu, podendo questionar a validade do seu diagnóstico, como também prescrever uma dose maior do mesmo medicamento, ou ainda alterar a terapia medicamentosa a qual pode ser menos eficaz e ter um índice de efeitos adversos maior que a terapia inicial. Da mesma forma, pacientes que deixam de cumprir as instruçóes podem experimentar sérias deterioraçóes de suas condições, de maneira a pôr em risco a sua saúde. Além disso, 
pacientes que não aderem à terapia não apenas reduzem os benefícios e aumentam os riscos dos medicamentos mas também aumentam os custos de si mesmos e também do sistema de saúde.

A adesão à terapia pode ser avaliada pelo grau de concordância entre o comportamento de um doente em tomar os medicamentos, seguir dietas, alterar estilos de vida e as orientaçóes dadas pelos profissionais de saúde. Quando revisamos a literatura sobre a adesão do paciente à terapia medicamentosa, encontramos estimativas que variam entre $4 \%$ e $92 \%$, com uma média de adesáo nas patologias crônicas entre $50 \%$ e $65 \%$. Muitas são as razóes apontadas para a fraca adesão à terapia medicamentosa, e perceber as razôes do fracasso na adesão à terapêutica não é tarefa fácil, visto que os comportamentos de cada indivíduo, nomeadamente os comportamentos de saúde, são uma resultante de todos os fatores que influenciam a vida de cada um. Nenhum fator é determinante da adesão, mas, em diferentes graus, todos eles influenciam.

Talvez os conhecimentos do paciente facilitem um maior cumprimento do tratamento, favorecendo comportamentos específicos de conservação e promoção de saúde. Em geral, as terapias complexas não se seguem, e possivelmente exista pouco cumprimento dos tratamentos cujos propósitos e finalidades náo tenham sido expostos de forma clara e inteligível por parte dos profissionais de saúde. A educação do paciente, tanto sobre a doença, como sobre seu tratamento, é um fator fundamental que se deve ter em conta. Muito embora o reconhecimento de algo por si só náo seja um indicador de mudança de conduta, se tem demonstrado que certa quantidade de informação é necessária para iniciar o processo que conduzirá a uma mudança de comportamento.

Ao abordar este tema, espera-se ressaltar a importância educacional dos profissionais de saúde, em particular os médicos, enfermeiros e farmacêuticos no que diz respeito à avaliação, prescrição, educação e administração dos medicamentos ao paciente idoso, permitindo desta forma que certas estratégias cheguem a ser mais debatidas.

A mudança demográfica deveria trazer consigo uma nova maneira de pensar sobre o processo de envelhecimento. Nossa sociedade e o governo ainda não têm a noçáo adequada de como proporcionar um envelhecimento digno e com qualidade.

\section{Referências}

1. Rosenfeld, S. Prevalência, fatores associados e mau uso de medicamentos entre os idosos: uma revisão. Cad Saúde Pública 2003;19(3):717-24. 